\title{
Peroxidase Content per Single Myeloid Cell and in Plasma - Its Clinical Significance in Pediatrics
}

\author{
By \\ Noriko Katsushima \\ From the Department of Pediatrics, Faculty of Medicine, Tohoku \\ University, Sendai; Director: Prof. Ts. Arakawa
}

(Received for publication, January 30, 1963)

Very little is known about the physiological function of animal peroxidases, and clinical significance of peroxidase in human blood remains to be solved.

The author had devised new colorimetric methods for estimation of peroxidase activity in plasma ${ }^{1)}$ and per single myeloid cell. ${ }^{2}$ By using these methods the peroxidase activity was estimated in plasma and per single myeloid cell of the peripheral blood from normal and sick children in order to try to investigate the clinical significance of blood peroxidase.

One of the most noteworthy findings of the present investigation was that an abnormally high value for peroxidase per single myeloid cell was found in all the 4 children with neoplasm.

\section{METHOD AND MATERIALS}

The methods for the estimation of peroxidase in plasma and per single myeloid cell were the same as described in our preceding papers. ${ }^{1,2)}$

The normal subjects consisted of 32 children and 11 adults. As for pathologic conditions 101 cases with various kinds of disorders were subjected to this investigation.

\section{RESULTS AND DISCUSSION}

Normal value for plasma peroxidase (cf. Tables I \& II)

As was shown in Tables I \& II mean values \pm standard deviation for plasma peroxidase from the normal subjects were found to be $0.031 \pm 0.016 \gamma / \mathrm{ml}$ at the age of $0-1$ year, $0.058 \pm 0.037 \gamma / \mathrm{ml}$ at the age of $2-5$ years, $0.045 \pm 0.019$ $\gamma / \mathrm{ml}$ at the age of $6-12$ years, and $0.039 \pm 0.011 \gamma / \mathrm{ml}$ in adults. As was seen from 
Table I. Peroxidase Content in Plasma and per Single Myeloid Cell from Normal Subjects

\begin{tabular}{|c|c|c|c|c|c|c|}
\hline $\begin{array}{l}\text { Range } \\
\text { of age }\end{array}$ & $\begin{array}{c}\text { Age } \\
\text { (years and } \\
\text { months) }\end{array}$ & Sex & $\begin{array}{l}\text { Total white } \\
\text { cell count } \\
\text { per } \mathrm{mm}^{3} \text { of } \\
\text { the peripheral } \\
\text { blood }\end{array}$ & $\begin{array}{l}\text { Total count } \\
\text { of myeloid } \\
\text { cells per } \mathrm{mm}^{3} \\
\text { of the periphe- } \\
\text { ral blood }\end{array}$ & $\begin{array}{l}\text { Peroxidase } \\
\text { content per } \\
\text { single myeloid } \\
\text { cell }\left(\gamma \times 10^{-8}\right)\end{array}$ & $\begin{array}{l}\text { Peroxidase } \\
\text { content in } \\
\text { plasma } \\
\qquad(\gamma / \mathrm{ml})\end{array}$ \\
\hline $\begin{array}{l}\vec{z} \\
\mathbb{D} \\
\vec{D} \\
\overrightarrow{0}\end{array}$ & $\begin{array}{l}0-6 \\
0-7 \\
0-9 \\
0-8 \\
0-7 \\
0-9 \\
1-5 \\
1-9\end{array}$ & 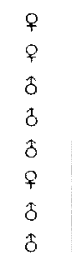 & $\begin{array}{r}8,600 \\
8,850 \\
13,400 \\
10,150 \\
11,700 \\
10,200 \\
6,150 \\
9,750\end{array}$ & $\begin{array}{l}2,480 \\
3,450 \\
5,900 \\
4,880 \\
4,740 \\
4,100 \\
3,030 \\
5,220\end{array}$ & $\begin{array}{l}6.85 \\
6.48 \\
7.66 \\
5.17 \\
6.73 \\
6.13 \\
5.55 \\
7.00\end{array}$ & $\begin{array}{l}0.017 \\
0.041 \\
0.035\end{array}$ \\
\hline \multirow[t]{2}{*}{ 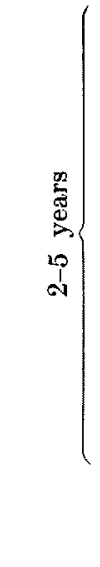 } & $\begin{array}{l}3 \\
3 \\
3 \\
4 \\
4 \\
4 \\
5 \\
5 \\
5 \\
5 \\
5 \\
5 \\
5 \\
5 \\
5\end{array}$ & 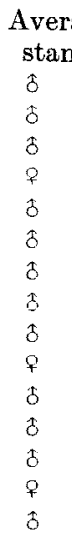 & $\begin{array}{l}\text { ge } \pm \\
\text { dard deviation } \\
9,850 \\
8,100 \\
6,850 \\
7,100 \\
9,500 \\
10,500 \\
10,200 \\
8,500 \\
7,800 \\
9,500 \\
8,100 \\
8,700 \\
6,050 \\
9,100 \\
9,550\end{array}$ & $\begin{array}{l}6,850 \\
4,370 \\
4,590 \\
3,550 \\
5,350 \\
4,830 \\
5,040 \\
5,650 \\
4,870 \\
6,270 \\
4,790 \\
4,870 \\
2,990 \\
5,840 \\
5,750\end{array}$ & $\begin{array}{c}6.45 \pm 0.81 \\
10.31 \\
5.50 \\
5.23 \\
10.00 \\
9.65 \\
4.18 \\
8.05 \\
8.95 \\
9.50 \\
5.95 \\
8.60 \\
7.00 \\
6.27 \\
9.94 \\
9.66\end{array}$ & $\begin{array}{c}0.031 \pm 0.019 \\
0.082 \\
0.141 \\
0.042 \\
0.071 \\
0.112 \\
0.063 \\
0.056 \\
0.024 \\
0.045 \\
0.041 \\
0.063 \\
0.026 \\
0.041 \\
0.036 \\
0.030\end{array}$ \\
\hline & & \multicolumn{2}{|c|}{$\begin{array}{l}\text { Average } \pm \\
\text { standard deviation }\end{array}$} & & $7.81 \pm 2.05$ & $0.058 \pm 0.037$ \\
\hline
\end{tabular}

Fig. 1 it was likely that high values for the plasma peroxidase were found more frequently at the age of $2-5$ years than in the other age groups (cf. Fig. 1).

Normal value for peroxidase per single myeloid cell (cf. Tables I \& II)

As was seen from Tables I \& II mean values \pm standard deviation for peroxidase per single myeloid cell from the normal subjects were $(6.45 \pm 0.81 \gamma) \times$ $10^{-8}$ at the age of $0-1$ year, $(7.81 \pm 2.05 \gamma) \times 10^{-8}$ at the age of $2-5$ years, $(7.31 \pm$ $0.91 \gamma) \times 10^{-8}$ at the age of $6-12$ years, and $(5.53 \pm 1.23 \gamma) \times 10^{-8}$ in adults. As was seen from Fig. 2, there was such a tendency that the peroxidase content per single myeloid cell was higher in children, especially in those of the age of $2-5$ years, than in adults (cf. Fig. 2). 
Table II. Peroxidase Content in Plasma and per Single Myeloid Cell from Normal Subjects

\begin{tabular}{|c|c|c|c|c|c|c|}
\hline $\begin{array}{l}\text { Range } \\
\text { of age }\end{array}$ & $\begin{array}{c}\text { Age } \\
\text { (years) }\end{array}$ & Sex & $\begin{array}{l}\text { Total white } \\
\text { cell count in } \\
\mathrm{mm}^{3} \text { of the } \\
\text { peripheral } \\
\text { blood }\end{array}$ & $\begin{array}{l}\text { Total count } \\
\text { of myeloid } \\
\text { cells in } \mathrm{mm}^{3} \\
\text { of the periphe- } \\
\text { ral blood }\end{array}$ & $\begin{array}{l}\text { Peroxidase } \\
\text { content per } \\
\text { single myeloid } \\
\text { cell }\left(\gamma \times 10^{-8}\right)\end{array}$ & $\begin{array}{l}\text { Peroxidase } \\
\text { content in } \\
\text { plasma } \\
\qquad(\gamma / \mathrm{ml})\end{array}$ \\
\hline $\begin{array}{l}\infty \\
2 \\
8 \\
0 \\
0 \\
0 \\
0 \\
0\end{array}$ & $\begin{array}{r}6 \\
6 \\
7 \\
8 \\
7 \\
9 \\
10 \\
12 \\
12\end{array}$ & $\begin{array}{l}q \\
5 \\
q \\
q \\
q \\
q \\
q \\
q \\
8\end{array}$ & $\begin{array}{r}9,250 \\
9,240 \\
7,250 \\
10,200 \\
8,650 \\
7,200 \\
9,950 \\
5,900 \\
7,950\end{array}$ & $\begin{array}{l}5,280 \\
6,000 \\
4,640 \\
4,540 \\
5,200 \\
4,250 \\
5,470 \\
4,070 \\
5,300\end{array}$ & $\begin{array}{l}7.87 \\
5.41 \\
7.86 \\
7.74 \\
8.30 \\
6.50 \\
7.80 \\
6.75 \\
7.60\end{array}$ & $\begin{array}{l}0.041 \\
0.019 \\
0.054 \\
0.032 \\
0.019 \\
0.067 \\
0.057 \\
0.038 \\
0.073\end{array}$ \\
\hline \multirow[t]{2}{*}{ 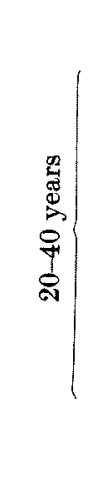 } & $\begin{array}{l}26 \\
42 \\
37 \\
34 \\
26 \\
26 \\
20 \\
20 \\
23 \\
28 \\
27\end{array}$ & 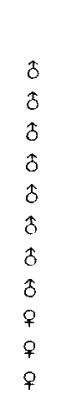 & $\begin{array}{c}\text { Average } \pm \text { sta } \\
\begin{array}{c}6,000 \\
6,150 \\
7,200 \\
7,800 \\
7,800 \\
6,600 \\
5,050 \\
8,200 \\
6,000 \\
7,200 \\
7,800\end{array}\end{array}$ & $\begin{array}{l}\text { dard deviation } \\
\qquad \begin{array}{c}3,420 \\
4,150 \\
4,650 \\
5,420 \\
5,340 \\
3,860 \\
2,600 \\
5,000 \\
4,200 \\
5,100 \\
5,300\end{array}\end{array}$ & $\begin{array}{c}7.31 \pm 0.91 \\
4.35 \\
8.07 \\
4.20 \\
5.06 \\
5.62 \\
5.00 \\
4.01 \\
5.50 \\
5.62 \\
5.24 \\
6.06\end{array}$ & $\begin{array}{c}0.045 \pm 0.019 \\
0.039 \\
0.023 \\
0.026 \\
0.054 \\
0.026 \\
0.042 \\
0.056 \\
0.051 \\
0.035 \\
0.035 \\
0.039\end{array}$ \\
\hline & & & \multicolumn{2}{|c|}{ Average \pm standard deviation } & $5.53 \pm 1.23$ & $0.039 \pm 0.011$ \\
\hline
\end{tabular}

Relation between peroxidase content in plasma and that per single myeloid cell in the normal subjects

No significant correlation was found between the peroxidase content in plasma and that per single myeloid cell, as was shown in Fig. 3 (cf. Fig. 3).

Peroxidase content in plasma and per single cell from the subjects with various kinds of disorders

The peroxidase content both in plasma and per single myeloid cell was estimated simultaneously upon 101 cases with various kind of disorders. In most cases the determination of peroxidase was carried out before any effective medical treatment was given. Total and differential counts of leukocytes in peripheral blood were simultaneously determined on these subjects, in order to know whether or not the peroxidase content per single cell or in plasma was related with the blood picture. 


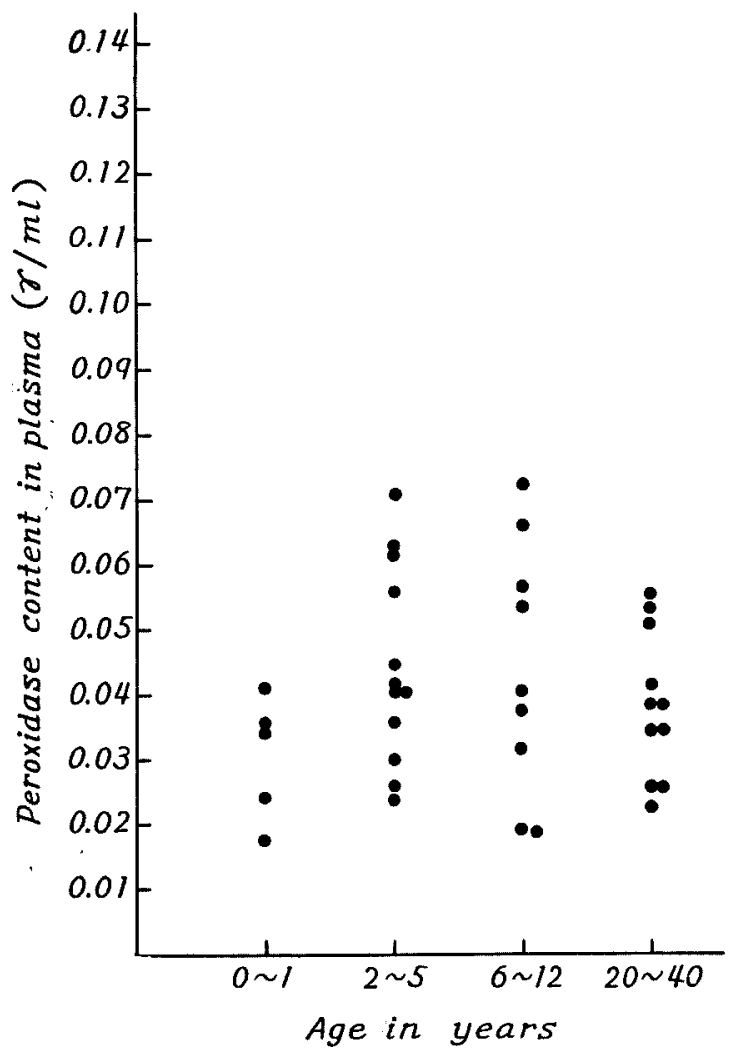

Fig. 1. Peroxidase content in plasma from normal subjects.

The results were given in Tables III-XII according to the kind of disorders.

In this paper a term of "abnormal value for peroxidase activity" was used from view-point of clinical evaluation of the peroxidase activity in plasma and per single myeloid cell. It was used provisionally in the following way; - when peroxidase content per single myeloid cell was below $4 \times 10^{-8} \gamma$ or above $12 \times 10^{-8} \gamma$, it was defined as "abnormal"; and when peroxidase content in plasma was below $0.02 \gamma / \mathrm{ml}$ or above $0.1 \gamma / \mathrm{ml}$, it was "abnormal" likewise.

Leukemia (cf. Table III)

As was seen in Nos. 1 and 6 in Table III, myeloblasts which were peroxidase negative to the Tohoku Pediatric stain ${ }^{6}$ ) did not show any of peroxidase activity by means of my own chemical method. This might be an expected result because benzidine, as a chromogen, was used in common in both the histochemical and my chemical methods. In this respect Loeb and Doniger's?) experiment upon 


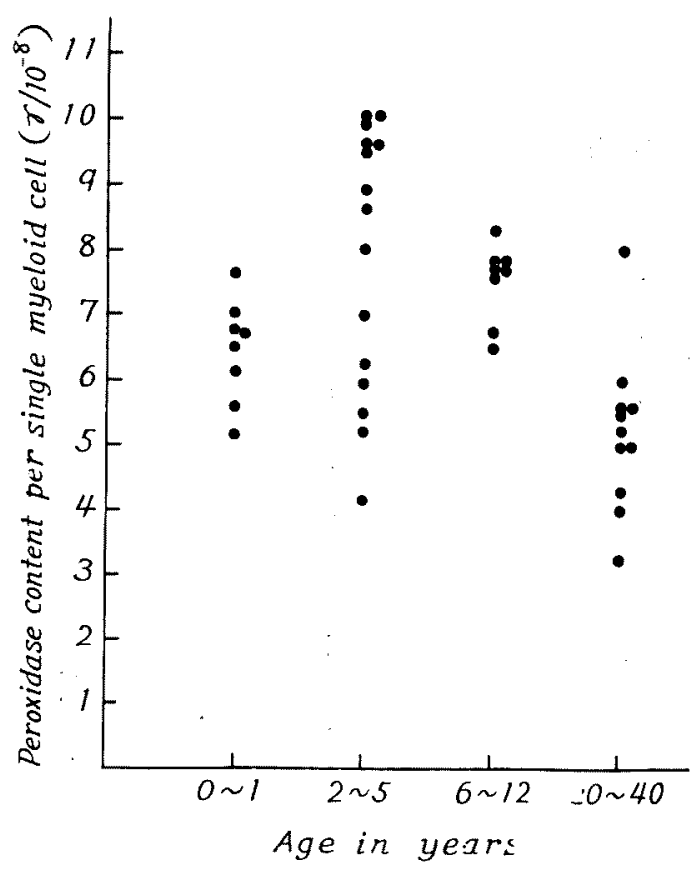

Fig. 2. Peroxidase content per single myeloid cell from the normal subjects.

chloroma of rats should be mentioned, in which peroxidase activity of the chloroma tissues was not detected by histochemical method, but could be detected by a certain chemical method.

As was seen in No. 7 in Table III, peroxidase positive myeloblasts showed a low peroxidase activity per single myeloblast.

In the cases with peroxidase negative myeloblastic leukemia (Nos. 2-5), peroxidase per single myeloid cell showed a normal value, this normal result will be considered as to be due to that in this case the peroxidase was derived from the nonleukemic myeloid cells.

Nos. 9 and 10 were the cases with acute myeloid leukemia in which both the peroxidase positive and negative myeloblasts, promyelocytes, myelocytes and metamyelocytes were found. In these cases normal values for peroxidase activity per single myeloid cell were found.

As regards plasma peroxidase levels, the extremely high values were found in the cases with peroxidase positive myeloblastic leukemia (Nos. $7 \& 8$ ). Such high values had not been found in any of the cases examined up to the present time. Kwasniwski and Henning, ${ }^{8)}$ and Bünte and Demling ${ }^{3)}$ reported an increase in serum peroxidase in myeloid leukemia and they were of the opinion that it was 


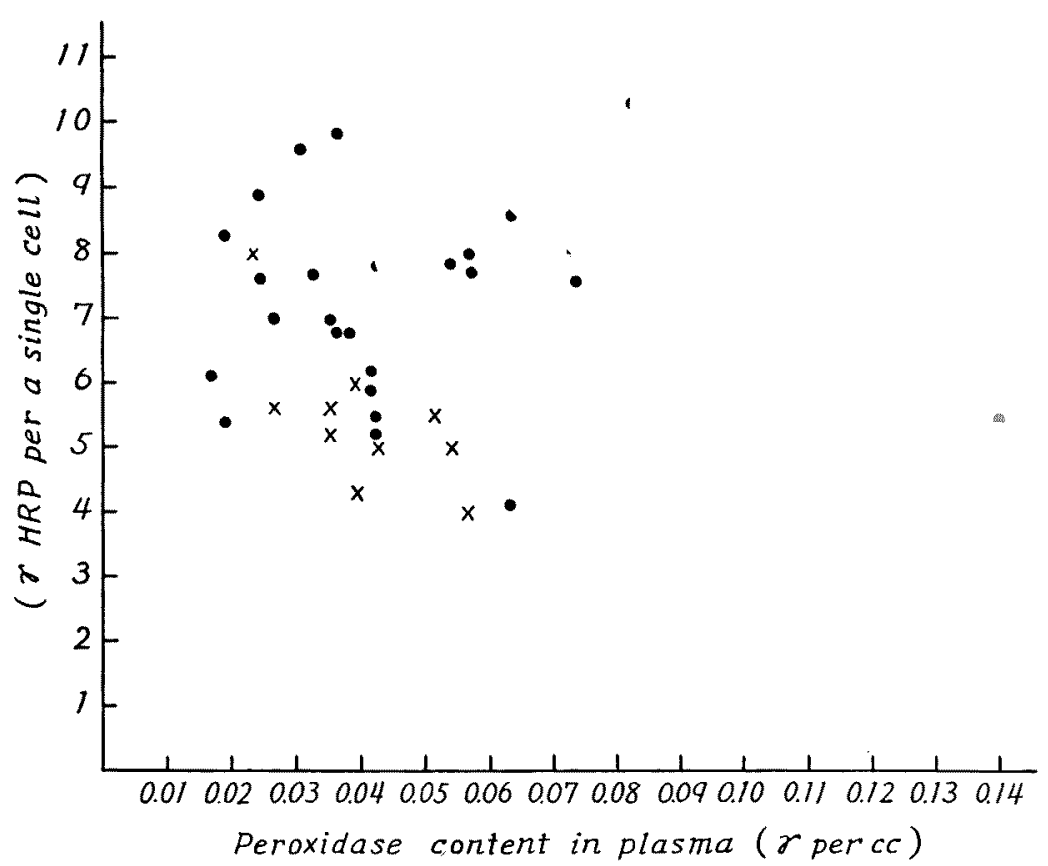

Fig. 3. Relation between peroxidase content in plasma and that per single myeloid cell in the cases of normal subjects.

- represents values from children under 12 years of age.

$\times$ represents those from adults.

due to a release of peroxidase from disintegrated leukocytes. A short life span of leukemic cells was reported by Weisberger and Levine. ${ }^{4)}$

Neoplasm (cf. Table IV)

The peroxidase levels of plasma were found to be within the normal range in 14 cases with neoplasm (Nos. 11-24 in Tab!e IV).

An abnormally high value for peroxidase per single myeloid cell was found in 7 cases out of the 13 cases examined, into which all the four cases of children (Nos. 11-14) and three cases (Nos. 19, 21, 23) of adults were included. In No. 17 abnormally low value of peroxidase activity per single myeloid cell was found. A complication with severe hypochromic anemia might be a contributing factor for low values of the peroxidase activity in this case (see below).

In 1958, Loeb and Doniger ${ }^{5)}$ investigated, by using a guajacol method, the peroxidase activity in bone marrow from the mice bearing neoplasm, and they found a progressive increase in bone marrow peroxidase activity in mice bearing the Ehrlich ascites carcinoma or Sarcoma 180. They stated that an increase in 
Table III. Peroxidase Content in Plasma and per

\begin{tabular}{|c|c|c|c|c|c|c|}
\hline \multirow[b]{2}{*}{$\begin{array}{l}\text { No. of } \\
\text { cases }\end{array}$} & \multirow[b]{2}{*}{ Name } & \multirow{2}{*}{$\begin{array}{l}\text { Sex } \\
\text { and } \\
\text { age }\end{array}$} & \multirow[b]{2}{*}{ Clinical diagnosis } & \multirow{2}{*}{$\begin{array}{l}\text { Total count } \\
\text { of white } \\
\text { cells } / \mathrm{mm}^{8}\end{array}$} & \multicolumn{2}{|c|}{ Leukemic cells } \\
\hline & & & & & $\%$ & $\begin{array}{c}\text { absolute } \\
\text { number/ } \\
\text { mm }^{3}\end{array}$ \\
\hline 1 & H.C. & $\delta, 2 y$ & $\begin{array}{l}\text { Peroxidase-negative } \\
\text { myeloblastic leukemia }\end{array}$ & 24,800 & 99 & 24,000 \\
\hline 2 & T.T. & $\hat{\jmath}, 3 \mathrm{y}$ & (" & 192,000 & 97 & 186,240 \\
\hline 3 & S.T. & s, 3y. & $"$ & 79,000 & 97 & 76,730 \\
\hline 4 & S.O. & $5,10 y$. & $"$ & 16,300 & 64 & 10,440 \\
\hline 5 & K.S. & $3,10 \mathrm{y}$ & " & 56,900 & 84.5 & 48,100 \\
\hline 6 & $\mathrm{~K} . \mathrm{T}$. & $9,10 \mathrm{y}$. & " & 2,800 & 100 & 2,800 \\
\hline 7 & T.S. & \&, $5 \mathrm{y}$. & Peroxidase positive & & & 19,200 \\
\hline & & & & 24,000 & 52.5 & 12,600 \\
\hline & & & & 25,350 & 35 & 9,000 \\
\hline & & & & 42,000 & 20 & 8,400 \\
\hline & & & & 30,900 & 52,5 & 16,200 \\
\hline 8 & H.K. & f, $13 \mathrm{y}$. & " & 39,400 & 95 & 37,400 \\
\hline 9 & M.K. & $\delta, 3 \mathrm{y}$ & Acute myeloid leukemia & 18,200 & 43 & 7,810 \\
\hline 10 & A.S. & \%, 13y. & $"$ & 8,700 & 40 & 3,480 \\
\hline
\end{tabular}

Table IV. Peroxidase Content in Plasma and per

\begin{tabular}{|c|c|c|c|c|c|c|c|}
\hline \multirow{3}{*}{$\begin{array}{l}\text { No. of } \\
\text { cases }\end{array}$} & \multirow{3}{*}{\multicolumn{2}{|c|}{$\begin{array}{l}\text { Name and } \\
\text { sex }\end{array}$}} & \multirow{3}{*}{$\begin{array}{c}\text { Age } \\
\text { (years) }\end{array}$} & \multirow{3}{*}{ Clinical diagnosis } & \multirow{3}{*}{$\begin{array}{l}\text { Total count } \\
\text { of white } \\
\text { cells } / \mathrm{mm}^{3}\end{array}$} & \multirow{2}{*}{\multicolumn{2}{|c|}{$\begin{array}{l}\text { Differential } \\
\text { Myeloid }\end{array}$}} \\
\hline & & & & & & & \\
\hline & & & & & & B & $\mathbf{E}$ \\
\hline 11 & K.N. & \& & 3 & Neuroblastoma & 4,800 & 0 & 4.5 \\
\hline 12 & A.K. & 3 & 3 & Craniopharyngioma & 11,400 & 0.5 & 3 \\
\hline 13 & T.U. & $\hat{\delta}$ & 15 & Craniopharyngioma & 8,800 & 0 & 2 \\
\hline 14 & F.M. & $\hat{0}$ & 7 & Brain tumor & 5,600 & 0 & 0.5 \\
\hline 15 & M.K. & $\hat{0}$ & 58 & Carcinoma of pancreas & 16,700 & 0 & 2.5 \\
\hline 16 & O.T. & \& & 59 & Stomach cancer & 6,750 & 0 & 3.5 \\
\hline 17 & M.A. & ? & 35 & Stomach cancer & 11,750 & 0 & 0.5 \\
\hline 18 & U.S. & 3 & 57 & Stomach cancer & 5,300 & 0 & 4 \\
\hline 19 & M.K. & 웅 & 53 & Esophageal cancer & 7,900 & 0 & 8.5 \\
\hline 20 & N.O. & $\hat{b}$ & 63 & Caricinoma of lung & 3,800 & 0 & 2.5 \\
\hline 21 & M.M. & 웅 & 42 & $\begin{array}{l}\text { Metastatic cancer of } \\
\text { cervical nodes }\end{array}$ & 11,950 & 0 & 9 \\
\hline 22 & S.S. & q & 41 & Breast cancer & 7,600 & 0 & 0.5 \\
\hline 23 & T.O. & 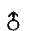 & 63 & Reticulosarcoma & 4,350 & 0 & 5.5 \\
\hline 24 & K.T. & q & 67 & Reticulosarcoma & 5,500 & 0 & 3.5 \\
\hline
\end{tabular}


Single Myeloid Cell in the Cases of Leukemia

\begin{tabular}{|c|c|c|c|}
\hline $\begin{array}{l}\text { Absolute number of } \\
\text { peroxidase positive } \\
\text { cells } / \mathbf{m m}^{\mathbf{3}}\end{array}$ & $\begin{array}{l}\text { Peroxidase content } \\
\text { per single myeloid } \\
\text { cell } \quad\left(\gamma \times 10^{-8}\right)\end{array}$ & $\begin{array}{l}\text { Peroxidase con- } \\
\text { tent in plasma } \\
\qquad(\gamma / \mathrm{ml})\end{array}$ & Remarks \\
\hline 0 & 0 & 0.043 & No medical treatment \\
\hline $\begin{array}{r}5,760 \\
2,270 \\
5,860 \\
4,550 \\
0\end{array}$ & $\begin{array}{r}7.46 \\
11.00 \\
6.57 \\
5.41 \\
0\end{array}$ & $\begin{array}{l}0.110 \\
0.013 \\
0.022 \\
0.037 \\
0.054\end{array}$ & $\begin{array}{l}\prime \prime \\
" 1 \\
\prime \prime \\
\prime \prime\end{array}$ \\
\hline $\begin{array}{l}19,200 \\
16,800 \\
11,300 \\
15,200 \\
21.600 \\
37,400\end{array}$ & 1.88 & $\begin{array}{l}0.260 \\
0.347 \\
0.165 \\
0.189 \\
0.268 \\
0.740\end{array}$ & $\begin{array}{l}\text { No medical treatment } \\
\left\{\begin{array}{l}\text { Treatment with } \\
\text { steroid and } 6-\mathrm{MP}\end{array}\right. \\
\text { No medical treatment }\end{array}$ \\
\hline $\begin{array}{l}7,600 \\
2,950\end{array}$ & $\begin{array}{l}6.73 \\
9.05\end{array}$ & $\begin{array}{l}0.086 \\
0.019\end{array}$ & $\begin{array}{l}\text { No medical treatment } \\
\text { Treatment with } \\
\text { steroid }\end{array}$ \\
\hline
\end{tabular}

Single Myeloid Cell from Cases with Neoplasm

\begin{tabular}{|c|c|c|c|c|c|c|c|}
\hline \multicolumn{4}{|c|}{ count of leukocytes $(\%)$} & \multirow{3}{*}{$\begin{array}{l}\% \text { of } \\
\text { band } \\
\text { form }\end{array}$} & \multirow{3}{*}{$\begin{array}{l}\text { Absolute } \\
\text { number of } \\
\text { myeloid } \\
\text { cells } / \mathrm{mm}^{3}\end{array}$} & \multirow{3}{*}{$\begin{array}{l}\text { Peroxidase } \\
\text { content per } \\
\text { single } \\
\text { myeloid cell } \\
\left(\gamma \times 10^{-8}\right)\end{array}$} & \multirow{3}{*}{$\begin{array}{l}\text { Peroxidase } \\
\text { content in } \\
\text { plasma } \\
\qquad(\gamma / \mathrm{ml})\end{array}$} \\
\hline \multicolumn{2}{|l|}{ cell } & \multirow{2}{*}{$\mathbf{L}$} & \multirow{2}{*}{$\begin{array}{l}\text { Virocyte } \\
\text { plasma cell }\end{array}$} & & & & \\
\hline $\mathbf{M}$ & $\mathrm{N}$ & & & & & & \\
\hline 5.5 & 44 & 46 & 0 & 36 & 2,600 & 14.00 & 0.071 \\
\hline 2.5 & 42.5 & 51.5 & 0 & 7 & 5,530 & 14.10 & 0.029 \\
\hline 4 & 58.5 & 35.5 & 1 & 21 & 5,670 & 12.32 & 0.059 \\
\hline 4 & 41 & 54.5 & 0 & 6 & 2,520 & 16.00 & 0.055 \\
\hline 2.5 & 85 & 10 & 0 & 11 & 15,030 & 8.45 & 0.062 \\
\hline 2 & 57 & 37.5 & 0 & 12 & 4,220 & 9.45 & 0.024 \\
\hline 3.5 & 89 & 7 & 0 & 13 & 10,880 & 3.99 & 0.043 \\
\hline 7 & 58 & 31 & 0 & 8 & 3,660 & 8.00 & 0.030 \\
\hline 5 & 79 & 5 & 0 & 17 & 7,270 & 14.08 & 0.040 \\
\hline 10.5 & 82 & 5 & 0 & 7 & 3,400 & 6.71 & 0.027 \\
\hline 4.5 & 82 & 4.5 & 0 & 16 & 11,410 & 13.81 & 0.025 \\
\hline 7 & 78 & 14.5 & 0 & 15 & 6,500 & 6.54 & 0.025 \\
\hline 7.5 & 71 & 16 & 0 & 27 & 3,650 & 13.80 & 0.024 \\
\hline 4 & 74 & 18.5 & 0 & 20 & 4,480 & 6.74 & 0.045 \\
\hline
\end{tabular}


Table V. Peroxidase Content in Plasma and per Single Myeloid Cell from a Child with Chronic Agranulocytosis

\begin{tabular}{|c|c|c|c|c|c|c|c|c|c|c|c|}
\hline \multirow{2}{*}{$\begin{array}{c}\text { No. } \\
\text { of } \\
\text { cases }\end{array}$} & \multirow{2}{*}{$\begin{array}{l}\text { No. of } \\
\text { exami- } \\
\text { nation }\end{array}$} & \multirow{2}{*}{$\begin{array}{l}\text { Total } \\
\text { count of } \\
\text { white } \\
\text { cells } / \mathrm{mm}^{2}\end{array}$} & \multicolumn{5}{|c|}{$\begin{array}{l}\text { Differential count } \\
\text { of leukocytes }(\%)\end{array}$} & \multirow{2}{*}{$\begin{array}{l}\text { Absolute } \\
\text { number of } \\
\text { myeloid } \\
\text { cells } / \mathrm{mm}^{3}\end{array}$} & \multirow{2}{*}{$\begin{array}{l}\text { Peroxidase } \\
\text { content per } \\
\text { single } \\
\text { myeloid } \\
\text { cell }\left(10^{-8} \gamma\right)\end{array}$} & \multirow{2}{*}{$\begin{array}{l}\text { Peroxi- } \\
\text { dase con- } \\
\text { tent in } \\
\text { plasma } \\
(\gamma / \mathrm{ml})\end{array}$} & \multirow{2}{*}{ Remarks } \\
\hline & & & B & $\mathbf{E}$ & M & $\mathrm{N}$ & L & & & & \\
\hline \multirow[t]{12}{*}{25} & 1 & 8,100 & 0 & 0 & 18.5 & \multicolumn{2}{|c|}{6.575} & 2,030 & 5.90 & 0.047 & \multirow{12}{*}{$\begin{array}{l}\text { Treated } \\
\text { with } \\
\text { steroid }\end{array}$} \\
\hline & 2 & 3,600 & 1 & 1 & 17 & & 75 & 900 & 3.80 & & \\
\hline & 3 & 1,200 & 0 & 0 & 40 & & 59 & 490 & 0.90 & 0.057 & \\
\hline & 4 & 7,200 & 0 & 0 & 34 & 3 & 63 & 2,670 & 1.39 & 0.052 & \\
\hline & 5 & 3,400 & 0 & 0. & 57 & 11 & 81.5 & 640 & 2.87 & 0.043 & \\
\hline & 6 & 5,750 & 0 & 0 & 36 & 3 & 61 & 2,350 & 2.83 & 0.083 & \\
\hline & 7 & 8,600 & 0 & 0 & 20 & 9 & 71 & 2,490 & 1.79 & 0.047 & \\
\hline & 8 & 8.200 & 1 & & 19 & 2.5 & & 2,900 & 18.60 & 0.067 & \\
\hline & 9 & 6,950 & $0-5$ & 0 & 13 & 3.5 & 83 & 1,140 & 5.87 & 0.053 & \\
\hline & 10 & 14,300 & 0 & 0 & 15.5 & 3.5 & 81 & 1,750 & 3.31 & & \\
\hline & 11 & 7,200 & 0 & 13 & 42.5 & 5.5 & 39 & 4,100 & 1.85 & & \\
\hline & 12 & 3,550 & 0 & 6 & 36 & 7 & 51 & 1,770 & 3.70 & & \\
\hline
\end{tabular}

Table VI. Peroxidase Content in Plasma and per Single

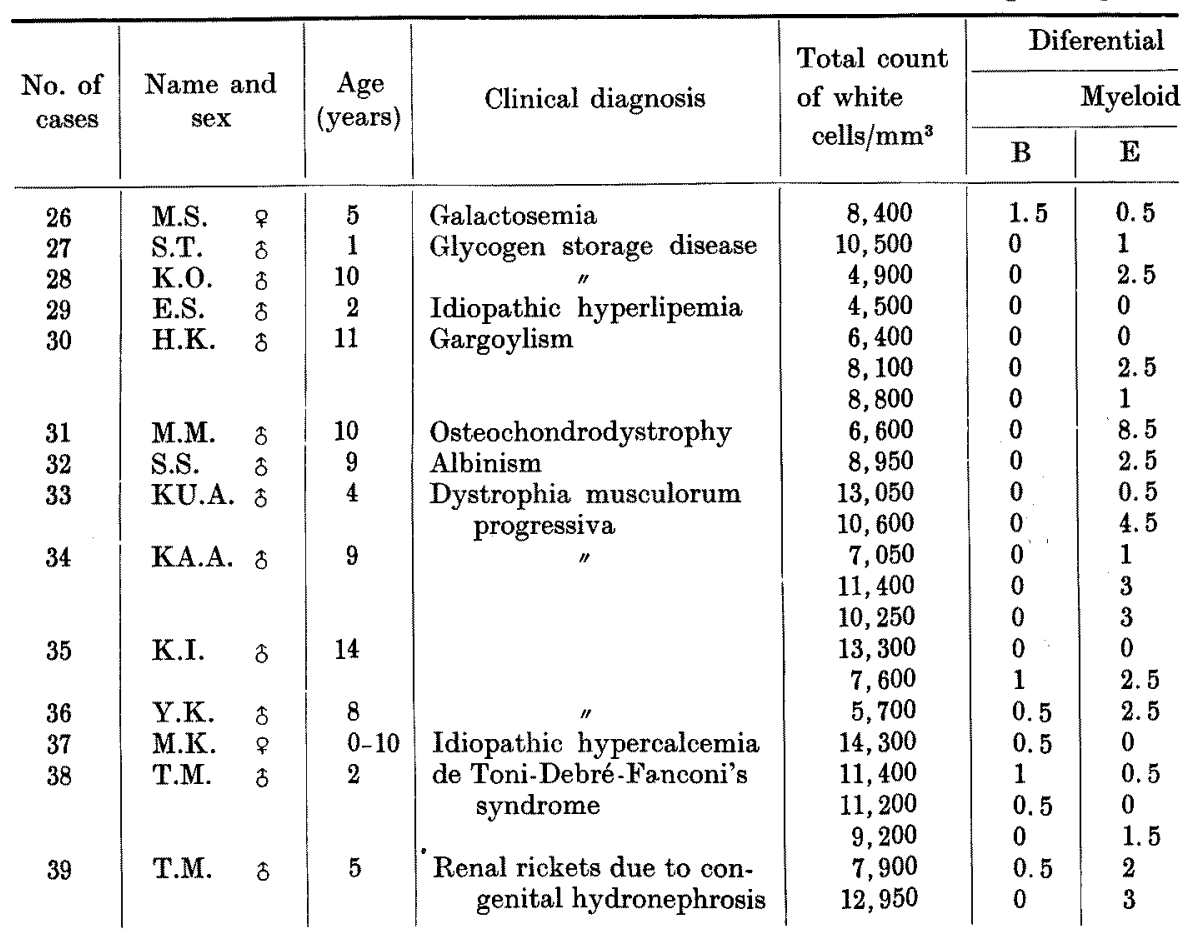


peroxidase activity in bone marrow of tumor bearing mice might be taken as an adaptive response, as in the case of reduced catalase in the liver of tumor bearing animals.

\section{Chronic agranulocytosis (cf. Table V)}

Basing upon our hematological observation of more than one year No. 25 was found to be a case with chronic agranulocytosis in which the majority of myeloid cells in the peripheral blood was consisted of monocytes. Peroxidase activity per single myeloid cell (monocyte) was abnormally low, but plasma peroxidase level remained within the normal range.

\section{Metabolic disorders (cf. Table VI)}

The plasma peroxidase levels were found to be within the normal limits in all the cases with metabolic disorders. The abnormally high values for peroxidase per single myeloid cell were found in glycogen storage disease (Nos. 27, 28), albinism (No. 32), Fanconi's syndrome (No. 38), and dystrophia musculorum progressiva (Nos. 33, 35), while the abnormally low values for peroxidase per single myeloid cell were found in gargoylism (No. 30), osteochondrodystrophy

Myeloid Cell from the Cases with Metabolic Disorders

\begin{tabular}{|c|c|c|c|c|c|c|c|}
\hline \multicolumn{4}{|c|}{ count of leukocytes (\%) } & \multirow{3}{*}{$\begin{array}{l}\% \text { of } \\
\text { band } \\
\text { form }\end{array}$} & \multirow{3}{*}{$\begin{array}{l}\text { Absolute } \\
\text { number of } \\
\text { myeloid } \\
\text { cells } / \mathrm{mm}^{3}\end{array}$} & \multirow{3}{*}{$\begin{array}{l}\text { Peroxidase } \\
\text { content } \\
\text { per single } \\
\text { myeloid cell } \\
\left(\gamma \times 10^{-8}\right)\end{array}$} & \multirow{3}{*}{$\begin{array}{l}\text { Peroxidase } \\
\text { content in } \\
\text { plasma } \\
\qquad(\gamma / \mathrm{ml})\end{array}$} \\
\hline \multicolumn{2}{|l|}{ cells } & \multirow{2}{*}{$\mathrm{L}$} & \multirow{2}{*}{$\begin{array}{c}\text { Virocyte } \\
\text { plasma cell }\end{array}$} & & & & \\
\hline $\mathbf{M}$ & $\mathbf{N}$ & & & & & & \\
\hline 2 & 47 & 49 & 0 & 9 & 3,290 & 5.96 & 0.021 \\
\hline 8.5 & 53 & 37.5 & 0 & 0 & 6,630 & 12.50 & 0.042 \\
\hline 2 & 47 & 48.5 & 0 & 28 & 2,250 & 11.90 & 0.030 \\
\hline 8.5 & 54 & 37.5 & 0 & 47 & 2,570 & 6.18 & 0.046 \\
\hline 3 & 54.5 & 42.5 & 0 & 7 & 3,680 & 3.00 & 0.032 \\
\hline 3.5 & 31.5 & 62.5 & 0 & 6 & 3,050 & 2.84 & 0.052 \\
\hline 2 & 42.5 & 54.5 & 0 & 4 & 3,310 & 5.65 & 0.033 \\
\hline 4 & 60 & 27.5 & 0 & 9 & 4,780 & 3.90 & 0.039 \\
\hline 4.5 & 63 & 30 & 0 & 2 & 6,770 & 16.40 & 0.021 \\
\hline 4 & 36.5 & 59 & 0 & 4 & 5,100 & 12.00 & \\
\hline 4 & 24. & 67.5 & 0 & 2 & 3,450 & 11.45 & \\
\hline 5.5 & 41 & 52.5 & 0 & 6 & 3,250 & 4.06 & \\
\hline 4.5 & 49.5 & 43 & 0 & 9 & 6,580 & 3.05 & 0.039 \\
\hline 3 & 39 & 55 & 0 & 20 & 4,620 & 5.52 & 0.027 \\
\hline 5 & 70.5 & 24.5 & 0 & 21 & 10,050 & 11.42 & 0.049 \\
\hline 6.5 & 57.5 & 32.5 & 0 & 15 & 5,130 & 18.65 & \\
\hline 5.5 & 40.5 & 50 & 0 & 7 & 5,130 & 7.26 & 0.055 \\
\hline 3 & 27.5 & 69 & 0 & 15 & 4,360 & 10.00 & 0.032 \\
\hline 7 & 33 & 58.5 & 0 & 5 & 5,240 & 4.56 & 0.026 \\
\hline 5 & 52 & 42.5 & 0 & 8 & 5,440 & 11.57 & 0.033 \\
\hline 2 & 46 & 50.5 & 0 & 10 & 4,550 & 12.12 & 0.053 \\
\hline 8 & 56.5 & 33 & 0 & 19 & 5,300 & 7.10 & 0.041 \\
\hline 2.5 & 72.5 & 22 & 0 & 10 & 10,100 & 6.61 & 0.084 \\
\hline
\end{tabular}


Table VII. Peroxidase Content in Plasma and per

\begin{tabular}{|c|c|c|c|c|c|c|c|}
\hline \multirow{3}{*}{$\begin{array}{l}\text { No. of } \\
\text { cases }\end{array}$} & \multirow{3}{*}{\multicolumn{2}{|c|}{$\begin{array}{c}\text { Name and } \\
\text { sex }\end{array}$}} & \multirow{3}{*}{$\begin{array}{c}\text { Age } \\
\text { (years) }\end{array}$} & \multirow{3}{*}{ Clinical diagnosis } & \multirow{3}{*}{$\begin{array}{l}\text { Total count } \\
\text { of white } \\
\text { cells } / \mathrm{mm}^{8}\end{array}$} & \multirow{2}{*}{\multicolumn{2}{|c|}{$\frac{\text { Differential }}{\text { Myeloid }}$}} \\
\hline & & & & & & & \\
\hline & & & & & & B & $\mathbf{E}$ \\
\hline 40 & A.F. & $\delta$ & $0-2$ & Osteomyelitis & 24,300 & 0 & 1 \\
\hline 41 & H.H. & $\hat{0}$ & 3 & Sepsis & 21,000 & 0 & 0 \\
\hline 42 & N.S. & $\hat{\delta}$ & 4 & Actue bronchitis & 11,000 & 0 & 0 \\
\hline 43 & J.K. & $\delta$ & 4 & Purulent meningitis & 9,400 & 0 & 0.5 \\
\hline 44 & Y.O. & 9 & 5 & Thoracic empyema & 12,700 & 0.5 & 3 \\
\hline 45 & J.K. & $\delta$ & 6 & Ecthyma & 6,950 & 0 & 3.5 \\
\hline 46 & E.H. & 8 & 7 & Thoracic empyema & 17,700 & 0 & 0 \\
\hline & & & & 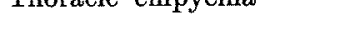 & 15,100 & 0 & 1 \\
\hline & & & & & 15,100 & 0 & 1.5 \\
\hline 47 & M.O. & $q$ & 10 & Tuberculous meningitis & 12,900 & 0 & 1 \\
\hline 48 & H.K. & 8 & 1 & Adenoconjunctivitis & 13,800 & 0 & 2 \\
\hline 49 & M.C. & $\hat{\delta}$ & $0-8$ & Infectious lymphocytosis & 21,100 & 0.5 & 2 \\
\hline 50 & Y.O. & 9 & 6 & Viral pleuritis & 18,500 & 0 & 3 \\
\hline 51 & Y.T. & q & 6 & $\begin{array}{c}\text { Primary atypical } \\
\text { pneumonia }\end{array}$ & 9,200 & 0 & 1.5 \\
\hline 52 & H.O. & $\delta$ & 9 & Rheumatic fever & 10,000 & 0 & 0 \\
\hline 53 & H.Y. & $\delta$ & 11 & Rheumatic fever & 8,000 & 0.5 & 4 \\
\hline 54 & T.O. & $\hat{\delta}$ & 13 & Rheumatic fever & 10,000 & 0 & 1 \\
\hline & & & & & 7,100 & 0 & 0 \\
\hline 55 & H.S. & 8 & 11 & Rheumatoid arthritis & 15,340 & 0 & 1.5 \\
\hline
\end{tabular}

Table VIII. Peroxidase Content in Plasma and per Single

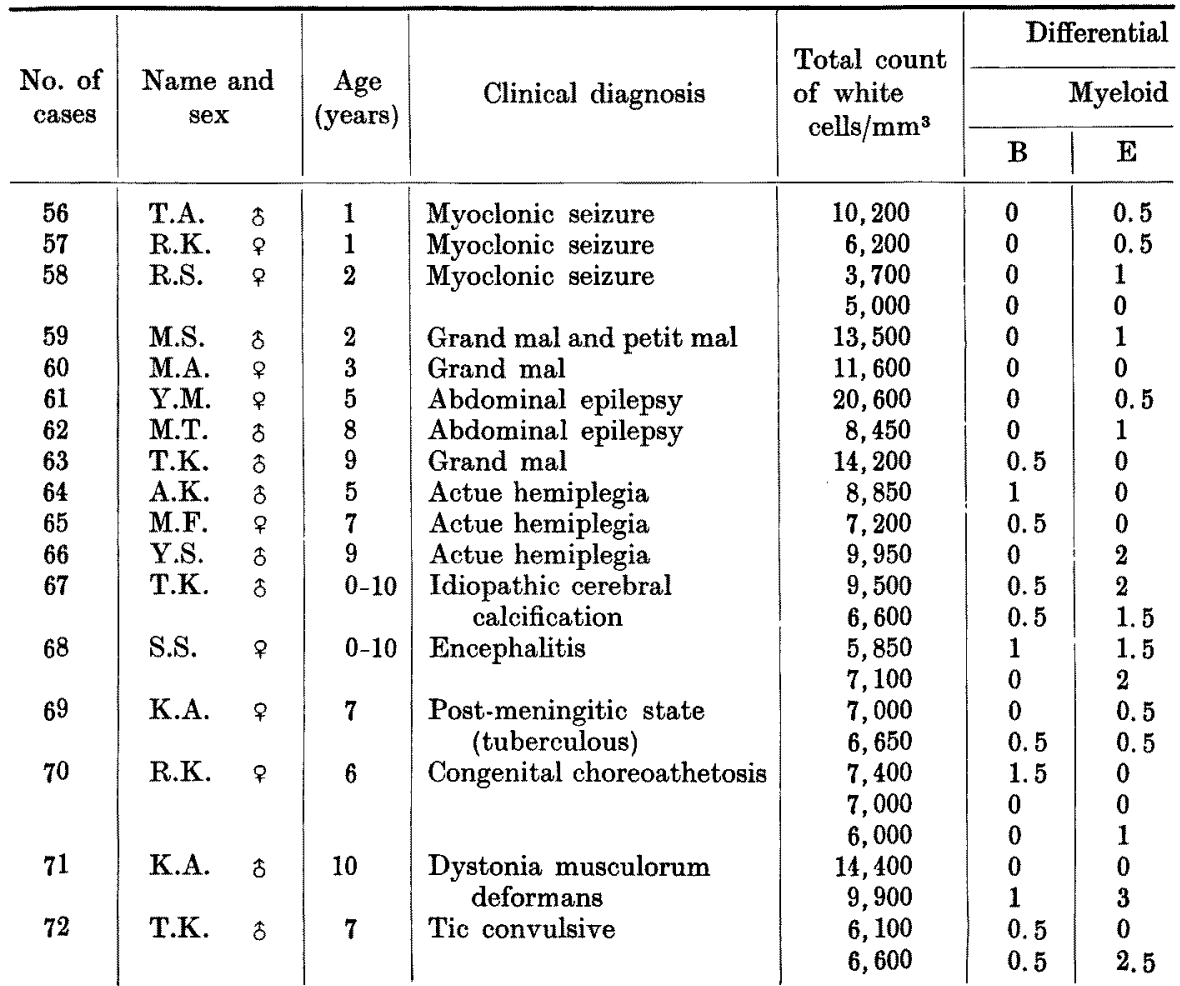


Single Myeloid Cell from the Cases with Infections

\begin{tabular}{l|l|l|l|r|r|r|r}
\hline \multicolumn{2}{l|}{ count of leukocytes (\%) } & $\begin{array}{c}\text { \% of } \\
\text { band } \\
\text { form }\end{array}$ & $\begin{array}{l}\text { Absolute } \\
\text { number of } \\
\text { myeloid } \\
\text { cells } / \mathrm{mm}^{8}\end{array}$ & $\begin{array}{l}\text { Peroxidase } \\
\text { content } \\
\text { per single } \\
\text { myeloid cell } \\
\left(\gamma \times 10^{-8}\right)\end{array}$ & $\begin{array}{l}\text { Peroxidase } \\
\text { content in } \\
\text { plasma } \\
(\gamma / \mathrm{ml})\end{array}$ \\
\hline M & N & L & $\begin{array}{l}\text { Virocyte } \\
\text { plasma cell }\end{array}$ & & & & \\
\hline 3 & 66 & 30 & 0 & 6 & 17,000 & 11.10 & 0.049 \\
1 & 85.5 & 13.5 & 0 & 17 & 18,130 & 9.45 & \\
3 & 81 & 16 & 0 & 6 & 9,240 & 7746 & 0.061 \\
4 & 61 & 34.5 & 0 & 12 & 6,160 & 8.30 & 0.049 \\
5 & 56.5 & 35 & 0 & 25 & 8,250 & 8.28 & 0.040 \\
6.5 & 46 & 44 & 0 & 30 & 3,920 & 14.00 & 0.027 \\
5 & 65 & 30 & 0 & 30 & 12,390 & 8.69 & 0.056 \\
1.5 & 45.5 & 52 & 0 & 4 & 7,200 & 3.90 & 0.023 \\
4 & 36.5 & 58 & 0 & 27 & 6,200 & 4.70 & 0.033 \\
7 & 82.5 & 9.5 & 0 & 34 & 11,650 & 10.00 & 0.056 \\
3 & 22 & 71.5 & 1.5 & 10 & 3,750 & 8.45 & \\
5.5 & 27 & 64 & 1 & 8 & 7,600 & 9.05 & 0.058 \\
3.5 & 67.5 & 26 & 0 & 10 & 13,690 & 4.72 & 0.055 \\
2.5 & 35.5 & 60.5 & 0 & 18 & 3,650 & 5.69 & 0.032 \\
& & & & & & & \\
1.5 & 73 & 25.5 & 0 & 11 & 7,650 & 7.25 & 0.093 \\
4 & 49.5 & 42 & 0 & 10 & 4,640 & 7.07 & 0.049 \\
3.5 & 65 & 30.5 & 0 & 8 & 6,950 & 15.95 & 0.057 \\
6.5 & 37 & 54.5 & 2 & 11 & 3,230 & 16.80 & 0.015 \\
2 & 85.5 & 11 & 0 & 24 & 15,340 & 3.92 & 0.014 \\
& & & & & &
\end{tabular}

Myeloid Cell from the Cases with Nervous Disorders

\begin{tabular}{|c|c|c|c|c|c|c|c|}
\hline \multicolumn{4}{|c|}{ count of leukcocytes $(\%)$} & \multirow{3}{*}{$\begin{array}{l}\% \text { of } \\
\text { band } \\
\text { from }\end{array}$} & \multirow{3}{*}{$\begin{array}{l}\text { Absolute } \\
\text { number of } \\
\text { myeloid } \\
\text { cells } / \mathrm{mm}^{3}\end{array}$} & \multirow{3}{*}{$\begin{array}{l}\text { Peroxidase } \\
\text { content } \\
\text { per single } \\
\text { myeloid cell } \\
\left(\gamma \times 10^{-8}\right)\end{array}$} & \multirow{3}{*}{$\begin{array}{l}\text { Peroxidase } \\
\text { content in } \\
\text { plasma } \\
\qquad(\gamma / \mathrm{ml})\end{array}$} \\
\hline cells & & \multirow{2}{*}{$\mathbf{L}$} & \multirow{2}{*}{$\begin{array}{c}\text { Virocyte } \\
\text { plasma cell }\end{array}$} & & & & \\
\hline $\mathbf{M}$ & $\mathbf{N}$ & & & & & & \\
\hline 5 & 27 & 67.5 & 0 & 7 & 3,301 & 7.17 & 0.095 \\
\hline 3.5 & 30.5 & 65.5 & 1 & 10 & 2,610 & 6.25 & 0.062 \\
\hline 3 & 63 & 31.5 & 1.5 & 20 & 2,540 & 7.75 & 0.072 \\
\hline 2.5 & 48.5 & 48 & 0 & 15 & 2,600 & 7.35 & 0.057 \\
\hline 4.5 & 46.5 & 47.5 & 0 & 10 & 7,080 & 8.22 & \\
\hline 3.5 & 65 & 31.5 & 0 & 9 & 7,970 & 6.22 & 0.066 \\
\hline 5.5 & 61 & 33 & 0 & 8 & 13,800 & 4.06 & 0.084 \\
\hline 4 & 66.5 & 28.5 & 0 & 10 & 6,040 & 8.49 & 0.072 \\
\hline 3.5 & 75 & 21 & 0 & 13 & 11,210 & 10.08 & \\
\hline 1.5 & 66.5 & 31 & 0 & 4 & 6,110 & 9.64 & 0.061 \\
\hline 4.5 & 43 & 52 & 0 & 2 & 3,460 & 6.07 & \\
\hline 3 & 50 & 45 & 0 & 11 & 5,470 & 6.98 & 0.039 \\
\hline 8 & 48 & 41.5 & 0 & 14 & 5,560 & 5.65 & 0.035 \\
\hline 9 & 32.5 & 56.5 & 0.5 & 16 & 2,850 & 7.59 & 0.047 \\
\hline 6.5 & 35 & 55.5 & 0 & 13 & 2,870 & 7.24 & 0.108 \\
\hline 6.5 & 60 & 31.5 & 0 & 19 & 4,870 & 10.02 & \\
\hline 2 & 24 & 0 & 0 & 10 & 1,850 & 9.38 & 0.074 \\
\hline 7.5 & 63.5 & 0.5 & 0.5 & 2 & 4,850 & 6.28 & 0.022 \\
\hline 6 & 62.5 & 30 & 0 & 5 & 5,190 & 11.80 & 0.026 \\
\hline 7.5 & 49.5 & 43 & 0 & 44 & 4,000 & 11. 10 & 0.061 \\
\hline 1 & 31 & 67 & 0 & 9 & 1,980 & 5.21 & 0.036 \\
\hline 2.5 & 76.5 & 21 & 0 & 6 & 11,360 & 4.22 & 0.040 \\
\hline 5.5 & 45.5 & 45 & 0 & 0 & 5,500 & 4.18 & 0.026 \\
\hline 7 & 59 & 33.5 & 0 & 5 & 3,190 & 6.06 & 0.037 \\
\hline 5 & 58 & 34 & 0 & 6 & 4,350 & 7.43 & 0.042 \\
\hline
\end{tabular}


TABLE IX. Peroxidase Content in plasma and per

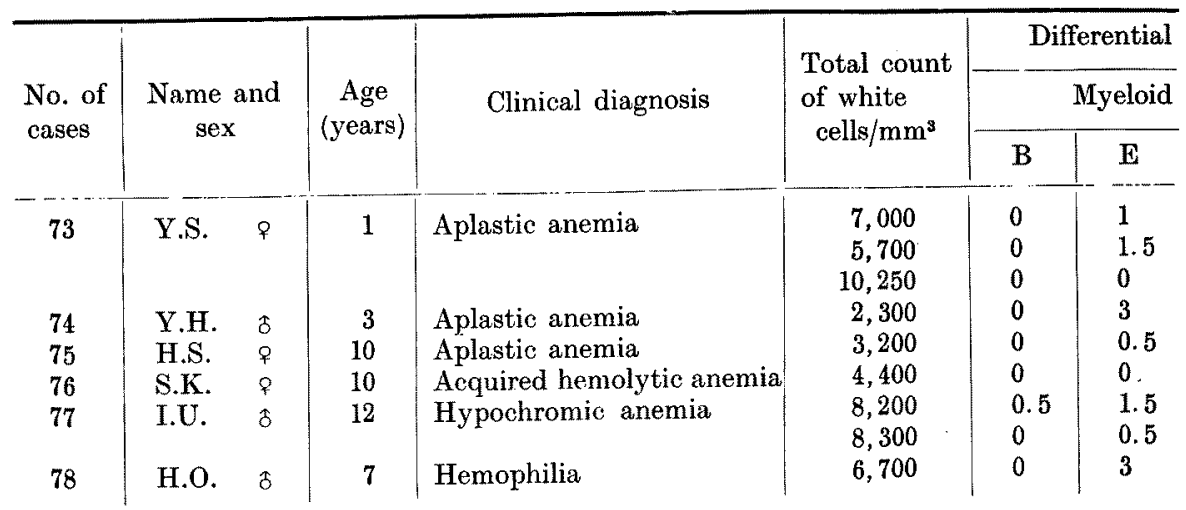

Table X. Peroxidase Content in Plasma and per

\begin{tabular}{|c|c|c|c|c|c|c|}
\hline \multirow{3}{*}{$\begin{array}{r}\text { No. of } \\
\text { cases }\end{array}$} & \multirow{3}{*}{$\begin{array}{l}\text { Name and } \\
\text { sex }\end{array}$} & \multirow{3}{*}{$\begin{array}{c}\text { Age } \\
\text { (years) }\end{array}$} & \multirow{3}{*}{ Clinical diagnosis } & \multirow{3}{*}{$\begin{array}{l}\text { Total count } \\
\text { of white } \\
\text { cells } / \mathrm{mm}^{3}\end{array}$} & \multirow{2}{*}{\multicolumn{2}{|c|}{$\frac{\text { Differential }}{\text { Myeloid }}$}} \\
\hline & & & & & & \\
\hline & & & & & $\mathbf{B}$ & $\mathbf{E}$ \\
\hline 79 & R.N. & 7 & Acute nephritis & 7,250 & 0 & 0.5 \\
\hline 80 & S.o. & 12 & Acute nephritis & 10,200 & 0 & 0 \\
\hline 81 & M.E. & 6 & Chronic nephritis & 12,600 & 0 & 0.5 \\
\hline 82 & Y.I. & 12 & Chronic nephritis & 6,750 & 0 & 2 \\
\hline
\end{tabular}

TABle XI. Peroxidase Content in Plasma and per

\begin{tabular}{|c|c|c|c|c|c|c|}
\hline \multirow{3}{*}{$\begin{array}{r}\text { No. of } \\
\text { cases }\end{array}$} & \multirow{3}{*}{$\begin{array}{c}\text { Name ano } \\
\text { sex }\end{array}$} & \multirow{3}{*}{$\begin{array}{c}\text { Age } \\
\text { (years) }\end{array}$} & \multirow{3}{*}{ Clinical diagnosis } & \multirow{3}{*}{$\begin{array}{l}\text { Total count } \\
\text { of white } \\
\text { cells } / \mathrm{mm}^{\mathrm{s}}\end{array}$} & \multirow{2}{*}{\multicolumn{2}{|c|}{$\frac{\text { Differential }}{\text { Myeloid }}$}} \\
\hline & & & & & & \\
\hline & & & & & $\mathbf{B}$ & $\mathrm{E}$ \\
\hline 83 & S.H. & 9 & Acute hepatitis & 11,000 & 0 & 0 \\
\hline 84 & C.N. & 5 & Chronic hepatitis & 4,050 & 0 & 5.5 \\
\hline 85 & G.K. & 4 & Cirrhosis of the liver & 9,400 & 0 & 0.5 \\
\hline 86 & T.S. & 7 & Lupoid hepatitis & 5,850 & 0 & 0.5 \\
\hline & & & & 8,400 & 0 & 0 \\
\hline 87 & R.C. & 10 & Plasma cell hepatitis & 5,300 & 0 & 0 \\
\hline 88 & M.K. & 12 & Cirrhosis of the liver & & & \\
\hline
\end{tabular}

(No. 31) and dystrophia musculorum progressiva (No. 34). Among these four cases of progressive muscular dystrophy, degeneration of the affected muscles was the most severe in No. 34 as compared with that in the other 3 cases (Nos. 33, 35, 36).

Infections (cf. Table VII)

The abnormally low values for plasma peroxidase were found in rheumatic 
Single Myeloid Cell from the Cases with Anemia

\begin{tabular}{|c|c|c|c|c|c|c|c|}
\hline \multicolumn{4}{|c|}{ count of leukocytes $(\%)$} & \multirow{3}{*}{$\begin{array}{l}\% \text { of } \\
\text { band } \\
\text { form }\end{array}$} & \multirow{3}{*}{$\begin{array}{l}\text { Absolute } \\
\text { number of } \\
\text { myeloid } \\
\text { cells } / \mathrm{mm}^{3}\end{array}$} & \multirow{3}{*}{$\begin{array}{l}\text { Peroxidase } \\
\text { content } \\
\text { per single } \\
\text { myeloid cell } \\
\left(\gamma \times 10^{-8}\right)\end{array}$} & \multirow{3}{*}{$\begin{array}{l}\text { Peroxidase } \\
\text { content in } \\
\text { plasma } \\
\qquad(\gamma / \mathrm{ml})\end{array}$} \\
\hline \multicolumn{2}{|l|}{ cells } & \multirow{2}{*}{$\mathrm{L}$} & \multirow{2}{*}{$\begin{array}{l}\text { Virocyte } \\
\text { plasma cell }\end{array}$} & & & & \\
\hline $\mathbf{M}$ & $\mathbf{N}$ & & & & & & \\
\hline 2 & 27 & 70 & 0 & 30 & 3,100 & 6.58 & 0.027 \\
\hline 2.5 & 55.5 & 40.5 & 0 & 9 & 3,310 & 13.50 & 0.044 \\
\hline 4.5 & 31.5 & 64 & 0 & 4 & 3,690 & 3. 36 & \\
\hline 1.5 & 29.5 & 55 & 0 & 16 & 800 & 7. 35 & 0.056 \\
\hline 3 & 57.5 & 38 & 0 & 6 & 1,970 & 5. 29 & 0.026 \\
\hline 8 & 60.5 & 31.5 & 0 & 14 & 3,020 & 2.02 & 0.043 \\
\hline 6.5 & 53.5 & 38 & 0 & 17 & 5,900 & 2.62 & 0.027 \\
\hline 13 & 48 & 38 & 0 & 21 & 3,990 & 3. 66 & 0.027 \\
\hline 7.5 & 48.5 & 40.5 & 0 & 4 & 3,990 & 8. 36 & 0.026 \\
\hline
\end{tabular}

Single Myeloid Cell from the Cases with Nephritis

\begin{tabular}{|c|c|c|c|c|c|c|c|}
\hline \multicolumn{4}{|c|}{ count of leukocytes $(\%)$} & \multirow{3}{*}{$\begin{array}{l}\% \text { of } \\
\text { band } \\
\text { form }\end{array}$} & \multirow{3}{*}{$\begin{array}{l}\text { Absolute } \\
\text { number of } \\
\text { myeloid } \\
\text { cells } / \mathrm{mm}^{\mathrm{s}}\end{array}$} & \multirow{3}{*}{$\begin{array}{l}\text { Peroxidase } \\
\text { content } \\
\text { per single } \\
\text { myeloid cell } \\
\left(\gamma \times 10^{-8}\right)\end{array}$} & \multirow{3}{*}{$\begin{array}{l}\text { Peroxidase } \\
\text { content in } \\
\text { plasma } \\
\quad(\gamma / \mathrm{ml})\end{array}$} \\
\hline cells & & \multirow{2}{*}{$\mathbf{L}$} & \multirow{2}{*}{$\begin{array}{l}\text { Virocyte } \\
\text { plasma cell }\end{array}$} & & & & \\
\hline $\mathbf{M}$ & $\mathrm{N}$ & & & & & & \\
\hline 4.6 & 59 & 36 & 0 & 12 & 4,640 & 7.75 & 0.062 \\
\hline 6.5 & 75.5 & 18 & 0 & 5 & 8,370 & 5.50 & 0.026 \\
\hline 3 & 80.5 & 15.5 & 0 & 12 & 10,300 & 4. 39 & 0.030 \\
\hline 7 & 59.5 & 31 & 0 & 15 & 6,350 & 10.04 & 0.037 \\
\hline 5.5 & 61.5 & 31 & 0 & 4 & 4,070 & 10.03 & 0.031 \\
\hline
\end{tabular}

Single Myeloid Cell from the Cases with Liver Diseases

\begin{tabular}{|c|c|c|c|c|c|c|c|}
\hline \multicolumn{4}{|c|}{ count of leukocytes $(\%)$} & \multirow{3}{*}{$\begin{array}{l}\% \text { of } \\
\text { band } \\
\text { form }\end{array}$} & \multirow{3}{*}{$\begin{array}{l}\text { Absolute } \\
\text { number of } \\
\text { myeloid } \\
\text { cells } / \mathrm{mm}^{3}\end{array}$} & \multirow{3}{*}{$\begin{array}{l}\text { Peroxidase } \\
\text { content } \\
\text { per single } \\
\text { myeloid cell } \\
\left(\gamma \times 10^{-8}\right)\end{array}$} & \multirow{3}{*}{$\begin{array}{l}\text { Peroxidase } \\
\text { content in } \\
\text { plasma } \\
\qquad(\gamma / \mathrm{ml})\end{array}$} \\
\hline cells & & \multirow{2}{*}{ L } & \multirow{2}{*}{$\begin{array}{l}\text { Virocyte } \\
\text { plasma cell }\end{array}$} & & & & \\
\hline $\mathbf{M}$ & $\mathbf{N}$ & & & & & & \\
\hline 5.5 & 42.5 & 52 & 0 & 8 & 5,280 & 4.41 & 0.028 \\
\hline 6 & 33 & 54.5 & 1 & 19 & 1,800 & 13.60 & 0.049 \\
\hline 4 & 61 & 34.5 & 0 & 12 & 6,160 & 8.30 & 0.046 \\
\hline 6 & 65.5 & 28 & 0 & 33 & 4,245 & 12.19 & 0.042 \\
\hline 2 & 71 & 26.5 & 0.5 & 43 & 6,150 & 12.95 & \\
\hline 4 & 54.5 & 41.5 & 0 & 20 & 3,100 & $\begin{array}{l}5.47 \\
1.31\end{array}$ & $\begin{array}{l}0.055 \\
0.035\end{array}$ \\
\hline
\end{tabular}

fever (No. 54) and rheumatoid arthritis (No. 55). As regards the peroxidase content per single myeloid cell, the abnormally high values were found in ecthyma (No. 45), and rheumatic fever (No. 54), and the abnormally low values in thoracic empyema (No. 46) and rheumatoid arthritis (No. 55).

Diseases of the nervous system (cf. Table VIII) 
Table XII. Peroxidase Content in Plasma and per Single

\begin{tabular}{|c|c|c|c|c|c|c|c|}
\hline \multirow{3}{*}{$\begin{array}{r}\text { No. of } \\
\text { cases }\end{array}$} & \multirow{2}{*}{\multicolumn{2}{|c|}{$\begin{array}{l}\text { Name and } \\
\text { sex }\end{array}$}} & \multirow{3}{*}{$\begin{array}{c}\text { Age } \\
\text { (years) }\end{array}$} & \multirow{3}{*}{ Clinical diagnosis } & \multirow{3}{*}{$\begin{array}{l}\text { Total count } \\
\text { of white } \\
\text { cells } / \mathrm{mm}^{\mathrm{s}}\end{array}$} & \multirow{2}{*}{\multicolumn{2}{|c|}{$\begin{array}{r}\text { Differential } \\
\text { Myeloid }\end{array}$}} \\
\hline & & & & & & & \\
\hline & & & & & & B & $\mathbf{E}$ \\
\hline 89 & H.M. & \& & 6 & Bronchial asthma & 6,000 & 0.5 & 6 \\
\hline 90 & J.S. & $\delta$ & 7 & Bronchial asthma & 8,350 & 0 & 1 \\
\hline 91 & C.o. & 3 & 10 & Cyclic vomiting & $\begin{array}{r}14,500 \\
9,200\end{array}$ & $\begin{array}{l}1.5 \\
0\end{array}$ & $\begin{array}{l}1 \\
0.5\end{array}$ \\
\hline 92 & Y.T. & 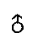 & 5 & Enuresis & 5,600 & 0 & 0.5 \\
\hline 93 & T.I. & $\delta$ & 1 & Cretinism & $\begin{array}{l}18,600 \\
12,000\end{array}$ & $\begin{array}{l}0 \\
0.5\end{array}$ & $\begin{array}{l}1 \\
3.5\end{array}$ \\
\hline 94 & S.S. & $\delta$ & 11 & Hypothyroidism & 8,350 & 0.5 & 2 \\
\hline 95 & F.S. & \& & 13 & Hypoparathyroidism & 3,600 & 0 & 1 \\
\hline 96 & H.S. & $q$ & $0-5$ & Dextrocardia & 20,500 & 0.5 & 0.5 \\
\hline 97 & T.K. & \& & $0-11$ & Pseudohermaphroditism & 7,600 & 0 & 1 \\
\hline 98 & M.K. & \& & 1 & Pseudohermaphroditism & 14,800 & 0 & 7 \\
\hline 99 & H.K. & $\delta$ & 3 & Incontinentia pigmenti & 9,750 & 1 & 1.5 \\
\hline 100 & T.M. & $\hat{s}$ & 4 & Hydroa vacciniforme & 7,350 & 0 & 2 \\
\hline 101 & K.W. & $\hat{t}$ & & & 8,150 & 0.5 & 1.5 \\
\hline 101 & & & 1 & Mongolism & 12,900 & 0 & 1.5 \\
\hline
\end{tabular}

No abnormal values for peroxidase in plasma and per single myeloid cell were found in the cases with nervous disorders, except a case of encephalitis (No. 68 ), in which a high plasma peroxidase level was found.

\section{Anemia (cf. Tab!e IX)}

The peroxidase levels in plasma were found to be within the normal range in all the cases examined. As regards the peroxidase content per single myeloid cell, the abnormally high values were found in aplastic anemia (No. 73), while the abnormally low values in acquired hemolytic anemia (No. 76) and hypochromic anemia( No. 77).

\section{Nephritis (cf. Table $\mathrm{X}$ )}

No abnormal values for peroxidase in plasma and per single myeloid cell were found in the cases with chronic or acute nephritis.

\section{Liver diseases (cf. Table XI)}

The plasma peroxidase levels were found to be within the normal limits in all the 6 cases with liver diseases, while abnormally high values for peroxidase per single myeloid cell were found in chronic hepatitis (No. 84) and lupoid hepatitis (No. 86).

\section{Miscellaneous diseases (cf. Table XII)}

The abnormally low values for plasma peroxidase were found in pseudo- 
Myeloid Cell from the Cases with Miscellaneous Disorders

\begin{tabular}{|c|c|c|c|c|c|c|c|}
\hline \multicolumn{4}{|c|}{ count of leukocyte $(\%)$} & \multirow{3}{*}{$\begin{array}{l}\% \text { of } \\
\text { band } \\
\text { form }\end{array}$} & \multirow{3}{*}{$\begin{array}{l}\text { Absolute } \\
\text { number of } \\
\text { myeloid } \\
\text { cells } / \mathbf{m m}^{3}\end{array}$} & \multirow{3}{*}{$\begin{array}{l}\text { Peroxidase } \\
\text { content } \\
\text { per single } \\
\text { myeloid cell } \\
\left(\gamma \times 10^{-8}\right)\end{array}$} & \multirow{3}{*}{$\begin{array}{l}\text { Peroxidase } \\
\text { content in } \\
\text { plasma } \\
\qquad(\gamma / \mathrm{ml})\end{array}$} \\
\hline cells & & \multirow{2}{*}{$\mathrm{L}$} & \multirow{2}{*}{$\begin{array}{l}\text { Virocyte } \\
\text { plasma cell }\end{array}$} & & & & \\
\hline $\mathbf{M}$ & $\mathbf{N}$ & & & & & & \\
\hline 4.5 & 47 & 42 & 0 & 16 & 3,480 & 7.25 & 0.052 \\
\hline 1.5 & 45 & 52.5 & 0 & 16 & 3,960 & 9.20 & \\
\hline 5 & 60 & 32.5 & 0 & 5 & 9,800 & 4.18 & 0.036 \\
\hline 1.5 & 75 & 23 & 0 & 9 & 7,080 & 5.08 & 0.038 \\
\hline 6.5 & 42.5 & 50 & 0.5 & 7 & 2,720 & 13.00 & \\
\hline 5.5 & 74 & 19.5 & 0 & 42 & 14,970 & 8.17 & 0.043 \\
\hline 6.5 & 32 & 57 & 0 & 17 & 5,150 & 10.01 & 0.065 \\
\hline 2.5 & 47 & 46.5 & 1.5 & 11 & 4,470 & 7.15 & 0.063 \\
\hline 4.5 & 69.5 & 25 & 0 & 13 & 2,250 & 10.08 & 0.027 \\
\hline 4.5 & 82 & 12.5 & 0 & 26 & 17,930 & 7.75 & 0.024 \\
\hline 5 & 59 & 35 & 0 & 11 & 3,940 & 8.25 & 0.017 \\
\hline 2 & 31.5 & 59.5 & 0 & 9 & 5,990 & 8.47 & 0.074 \\
\hline 4.5 & 33 & 60 & 0 & 10 & 3,900 & 6.40 & \\
\hline 6 & 40 & 52 & 0 & 5 & 3,450 & 11. 59 & 0.054 \\
\hline 2 & 37 & 59 & 0 & 4 & 3,350 & 11.89 & 0.065 \\
\hline 9 & 34.5 & 54.5 & 0.5 & 17 & 5,870 & 9.65 & 0.042 \\
\hline
\end{tabular}

hermaphroditism (No. 98), while an abnormally high value for peroxidase per single myeloid cell was found in enuresis (No. 92).

In any group examined no distinct relationship was found between the peroxidase content per single cell or in plasma and total or differential count of leukocytes in peripheral blood.

\section{SUMMARY}

A simultaneous estimation of peroxidase in plasma and per single myeloid cell was carried out by my own colorimetric method upon 42 normal subjects and 101 cases with various disorders. Even though the cases examined were small in number, a certain speculation could be drawn as was shown in Table XIII. The abnormally high values for peroxidase per single myeloid cell were found in the cases with neoplasm, mild form of progressive muscular dystrophy and lupoid hepatitis. Less probably it might be said that in the cases with chronic hepatitis, glycogen storage disease, albinism, ecthyma, sepsis and rheumatic fever an abnormally high level of peroxidase per single myeloid cell would be found.

The extremely high values for plasma peroxidase were found in the cases with the peroxidase positive myeloblastic leukemia. A considerable high value for plasma peroxidase was found in one case with encephalitis of unknown etiology.

The abnormally low levels for peroxidase per single myeloid cell were found in the cases with chronic agranulocytosis, and gargoylism, and less probably in the cases with hypochromic anemia, acquired hemolytic anemia, osteochondrodystrophy and rheumatoid arthritis. 
Table XIII. Summarized Table of Abnormal Peroxidase Values in Plasma or per Single Myeloid Cell, Basing upon the Results from 101 Cases Examined

\begin{tabular}{|c|c|c|c|c|}
\hline \multirow{2}{*}{$\begin{array}{l}\text { Mode of } \\
\text { abnormality in } \\
\text { peroxidase } \\
\text { value }\end{array}$} & \multicolumn{2}{|c|}{$\begin{array}{l}\text { Abnormally low } \\
\text { peroxidase value }\end{array}$} & \multicolumn{2}{|c|}{$\begin{array}{l}\text { Abnormally high } \\
\text { peroxidase value }\end{array}$} \\
\hline & $\begin{array}{l}\text { Per single } \\
\text { myeloid cell }\end{array}$ & $\begin{array}{l}\text { In } \\
\text { plasma }\end{array}$ & $\begin{array}{l}\text { Per single } \\
\text { myeloid cell }\end{array}$ & In plasma \\
\hline Probable & $\begin{array}{l}\text { Chronic } \\
\text { agranulocytosis } \\
\text { Gargoylism }\end{array}$ & & $\begin{array}{l}\text { Neoplasm } \\
\text { Dystrophia } \\
\text { musculorum } \\
\text { progressiva } \\
\text { (mild form) } \\
\text { Lupoid hepatitis }\end{array}$ & $\begin{array}{c}\text { Peroxidase- } \\
\text { positive } \\
\text { myeloblastic } \\
\text { leukemia }\end{array}$ \\
\hline Less probable & $\begin{array}{l}\text { Hypochromic } \\
\text { anemia } \\
\text { Acquired } \\
\text { hemolytic anemia } \\
\text { Osetochond- } \\
\text { rodystrophy } \\
\text { Rheumatoid } \\
\text { arthritis }\end{array}$ & & $\begin{array}{l}\text { Albinism } \\
\text { Ecthyma } \\
\text { Sepsis } \\
\text { Glycogen disease } \\
\text { Chronic hepatitis } \\
\text { Rheumatic fever }\end{array}$ & Encephalitis \\
\hline
\end{tabular}

\section{CONCLUSIONS}

A simultaneous estimation of the peroxidase activity in plasma and per single myeloid cell of peripheral blood was made upon 144 subjects with or without disease.

The method for the determination of peroxidase activity was my own colorimetric method which required only $3.5 \mathrm{ml}$ of blood. The results to be worthy of note were as follows:

1) For the peroxidase activity per single myeloid cell, an abnormally high value was found in the cases with neoplasm.

2) For the peroxidase activity in plasma, an abnormally high value was found in the cases with peroxidase-positive myeloblastic leukemia.

\section{References}

1) Katsushima, N. \& Arakawa, Ts., Tohoku J. Exper. Med., 1961, 75, 238.

2) Katsushima, N., ibid., 1963, 78, 339.

3) Bünte, U. \& Demling, L., Hoppe-Seyler's Zeitschr., 1958, 310, 107.

4) Weisberger, A.S. \& Levine, B., Blood, 1954, 9, 1082.

5) Loeb, H.G. \& Doniger, R., Brit. J. Cancer, 1958, 12, 669.

6) Sato, A. et al., Tohoku J. Exper. Med., 1934, 24, 195.

7) Loeb, H.G. \& Doniger, R., Brit. J. Cancer, 1959, 13, 506.

8) Kwasniewski, S. \& Henning, N., Klin. Wschr., 1925, 5, 1472. 